\title{
Labyrinthe
}

32 | 2009 (1)

Le petit théâtre intellectuel

\section{Hrant Dink ou L'« Intellectuel » post-mortem}

Le symbole d'une époque

\section{Vangelis Kechriotis}

Traducteur : Élodie Cassan et Marc Aymes

\section{(2) OpenEdition}

\section{Journals}

Édition électronique

URL : http://journals.openedition.org/labyrinthe/3993

DOI : $10.4000 /$ labyrinthe.3993

ISSN : 1950-6031

Éditeur

Hermann

Édition imprimée

Date de publication : 19 juin 2009

Pagination : 69-75

ISBN : 978-2-7056-6885-3

\section{Référence électronique}

Vangelis Kechriotis, «Hrant Dink ou L'« Intellectuel » post-mortem », Labyrinthe [En ligne], 32 | 2009 (1),

mis en ligne le 01 février 2011, consulté le 19 avril 2019. URL : http://journals.openedition.org/

labyrinthe/3993 ; DOI : 10.4000/labyrinthe.3993 


\section{HRANT DINK \\ OU L'" INTELLECTUEL " POST-MORTEM \\ Le symbole d'une époque}

Parler de Hrant Dink est rendu douloureux par son décès tragique. Hrant Dink a été assassiné à l'âge de 53 ans par un jeune fasciste, le 19 janvier 2007. En Turquie et ailleurs, ce meurtre a marqué un tournant dans la vie de bien des Turcs, des Arméniens, et d'autres. Beaucoup y ont vu l'expression de l'incapacité définitive de la société turque à devenir une société plurielle réellement démocratique. D'autres, au contraire, ont vu dans la foule de quelques centaines de milliers de personnes qui a suivi le cortège funéraire un espoir de renouveau et une possibilité de changement au plus profond des mentalités collectives. Ensuite s'est ouvert le procès de l'assassin et de ses complices présumés, qui se poursuit depuis lors: avant le début de chaque séance, des centaines de personnes continuent de se réunir aux portes du tribunal, et expriment leur détermination à suivre le procès de près pour obtenir une vraie justice, en rupture avec les prétextes fallacieux et les obstacles opposés par la bureaucratie turque. Les pancartes noires portées par ces personnes, depuis les funérailles de Dink, exhibent des messages tels que « Nous sommes tous des Arméniens », « Pour Hrant, pour la Justice », etc., écrits en turc, en arménien, mais aussi en kurde, en grec et en anglais.

Récemment, à l'occasion du second anniversaire de l'assassinat de Dink, des commémorations ont été organisées, et des articles écrits. L'un de ces articles a attiré particulièrement mon attention. Son auteur se proposait de discuter l'affirmation « Nous sommes tous des Hrant Dink ». Il disait qu'en réalité, nous ne le sommes pas. Il se lançait alors dans un commentaire des attitudes qui se voulaient des hommages aux idées de Hrant Dink, et il arrivait à la conclusion que lui-même ne pouvait pas aspirer à ressembler à ce journaliste turc arménien, décédé prématurément, tout simplement parce qu'il ne possédait pas ses qualités ${ }^{1}$.

\footnotetext{
1. Patrick Azadian, « On the inside, are we Hrant Dink? », Glendale News Press, 25 janvier 2009. Accessible en ligne: http://www.glendalenewspress.com/articles/2009/01/24/columns/gnp-margins24.txt.
} 
Hrant Dink est né à Malatya, une ville d'Anatolie centrale, en 1954. Sa famille a déménagé à Istanbul en 1961, après quoi ses parents ont divorcé. Dès lors, il a passé une grande partie de son enfance et de son adolescence dans un orphelinat arménien à Gedikpaşa, dans la vieille ville d'Istanbul. Cette expérience a marqué sa personnalité. Une fois devenu adulte, plusieurs années plus tard, il a consacré, avec sa femme, beaucoup d'énergie à administrer un camp des orphelins arméniens à Tuzla. Bien qu'il ait fait des études de zoologie et de philosophie à l'Université d'Istanbul, il a vite recherché différentes façons de transmettre sa vision politique et culturelle. Dès son plus jeune âge, il avait fait l'expérience des souffrances qu'entraînait la discrimination à l'encontre des minorités. Quand par la suite, il a dû faire son service militaire dans l'armée turque, le rang de caporal lui a été refusé simplement parce qu'il était Arménien. Néanmoins, en rupture avec l'attitude prévalant parmi les membres des communautés minoritaires, qui préféraient vivre sans prendre le risque de se faire remarquer et de mécontenter la majorité et l'État, lui était un activiste de gauche, qui eut à payer le prix de ses sympathies, comme d'ailleurs de nombreux Turcs et Kurdes, dans les difficiles années 19701980. Quand finalement, au début des années 1990, l'espace offert à l'opposition s'est élargi, Hrank Dink a ouvert une maison d'édition. En avril 1996, il franchit un pas décisif, avec quelques amis turcs et arméniens : il rompt le silence qui règne à l'intérieur de sa communauté en fondant un journal bilingue, Agos, dont le but est d'informer la majorité des problèmes rencontrées par la minorité, de contribuer à remettre en cause les frontières entre les deux, et de poser les droits du citoyen au fondement de l'union de tous les hommes entre eux.

Hrant Dink devient alors très célèbre en Turquie, moins en raison des articles critiques qu'il écrit pour son journal, dont le lectorat demeura longtemps assez restreint, que grâce aux débats publics (ou même, dans les dernières années de sa vie, aux programmes télévisés) auxquels il commence à prendre part. La douceur de sa manière de parler, combinée à une disposition naturelle au respect de tous les points de vue, révèlent à un public turc parfois surpris, n'ayant parfois jamais vu un Arménien participer à un débat auparavant, qu'il est possible de se réclamer d'une identité distincte de la leur tout en leur ressemblant beaucoup. Participer à de tels débats, exposer sa propre vérité à un public plus large, c'était pour le journaliste turc arménien une véritable mission. Cependant, la force 
de son talent n'a pas manqué de susciter des réactions. Ses déboires avec la justice turque remontent à 2002, quand il est accusé d'avoir « insulté l'identité turque », pour avoir déclaré, durant un colloque à Urfa : « Je ne suis pas un Turc, je suis un Arménien qui vis en Turquie ». Il est acquitté. En février 2004, néanmoins, il est pour la première fois ouvertement pris pour cible par la presse officielle, après avoir affirmé dans un article que Sabiha Gökçen, l'une des filles adoptives d'Atatürk, était en réalité d'origine arménienne. Cela lui vaut une mauvaise réputation dans les milieux nationalistes. En septembre 2005, au cours d'un colloque sur le destin des Arméniens à la fin de l'Empire ottoman - colloque tenu en dépit des oppositions et attaques orchestrées à son encontre, et qui a fait date dans l'histoire des discours publics sur le génocide arménien -, Hrank Dink prononce la communication la plus chargée d'émotion et la plus forte en répercussions. " Je ne me soucie pas, dit-il notamment, de savoir si vous allez parler ou non de génocide, parce que je sais ce qui est arrivé à mon peuple ». L'acmé de la communication est atteint lorsqu'il raconte l'histoire d'une vieille femme arménienne qui n'était rentrée chez elle, en Anatolie, que pour mourir peu après. Suite à cet événement, un paysan local avait suggéré que puisqu'elle et lui étaient unis par la même terre, il pouvait l'enterrer près de ses ancêtres musulmans à lui. «Ils disent que nous revendiquons un droit sur la terre d'Anatolie» conclut Dink, soulevant des vagues d'émotion dans l'assistance. « Oui c'est vrai, nous le revendiquons, mais non pour nous en emparer: pour y être inhumés profondément ». Personne ne pouvait imaginer alors que ce texte, et même parfois, l'enregistrement de sa voix durant cette journée, deviendraient l'une des références principales utilisées lors des événements dédiés à sa mémoire. Puis, en 2006, il est pour la seconde (et la plus traumatique) fois attaqué en justice. L'accusation repose cette fois sur le tristement célèbre article 301 du Code pénal, entré en vigueur en 2005, concernant les actes d'insultes à l'identité turque. Le procureur, à rebours des jugements émis par les experts, décide que Hrant Dink, qui a encouragé dans un discours ses concitoyens arméniens à se libérer de l'effet venimeux de la haine anti-turque sur leur psychologie, doit être condamné pour avoir soutenu que le sang turc était venimeux. Dink n'est condamné qu'à six mois de prison avec sursis, mais il est psychologiquement dévasté.

Le projet de son assassinat, mis à exécution quelques mois plus tard, était connu de nombreux officiers de police et bureaucrates de tous rangs, 
ainsi que l'ont établi les audiences du procès de son assassin présumé, en cours depuis plus d'un an. Le procès lui-même avance très lentement, plusieurs organisations d'État ayant déployé d'importants efforts pour éliminer les preuves ou empêcher les enquêtes. Pour autant, la pression de l'opinion, non seulement des personnes qui se réunissent devant le tribunal, mais aussi des médias, et même de certains politiciens, a finalement permis de mettre au jour des informations significatives, qui témoignent des liens entre cette affaire et l'autre grand procès qui trouble actuellement la Turquie, le dossier dit « Ergenekon ». Ce dernier a fourni des preuves substantielles qu'un coup d'État se préparait dès 2004, le projet des militaires et des civils impliqués étant d'organiser des assassinats de personnalités importantes, de façon à provoquer une situation chaotique et la proclamation de l'état d'urgence. On a pu soutenir que l'assassinat de Hrank Dink ferait partie de ce projet. Pour l'heure, il ne s'agit que de spéculations, mais cette hypothèse pourrait aider à comprendre les raisons de cet assassinat, ainsi que la personnalité de Dink et l'importance de ses contributions.

Une question s'est, dès le premier jour, posée avec force: Hrant Dink a-t-il été assassiné parce qu'il était de gauche, parce qu'il était Arménien, ou parce qu'il était un éditorialiste passionné qui parlait sans détour? Il ne faut pas oublier combien est longue la liste des personnalités publiques, spécialement des journalistes, qui ont été assassinées en Turquie. Pour beaucoup, le sort de Hrant Dink ne fait que s'inscrire dans cette série, si déplorable soit-elle. Mais sur la place d'Antalya, ville du Sud du pays, où les bustes de tous les journalistes assassinés en Turquie ont été placés les uns à côté des autres, on cherche en vain celui de Hrant Dink. La façon dont différentes parties de la population choisissent de commémorer un assassinat en dit long quant aux écarts de perception dont de tels événements sont l'objet. Cette année, la date du 19 janvier ainsi que les jours suivants ont été marqués par des commémorations en hommage à Hrant Dink, tandis que quelques jours plus tard, le 24 janvier, marquait l'anniversaire de l'assassinat d'un autre journaliste: Uğur Mumcu. Très connu pour ses articles critiques à l'égard des fondamentalistes islamistes ainsi que pour son soutien au sécularisme, il a été assassiné en 1993. Ses meurtriers n'ont jamais été retrouvés, mais il est clair qu'ils devaient être issus des cercles qu'il avait l'habitude de critiquer. Il serait intéressant de mener une recherche plus approfondie, mais il semble que la foule 